\title{
The whirligig of time
}

\author{
Anthony Ryle
}

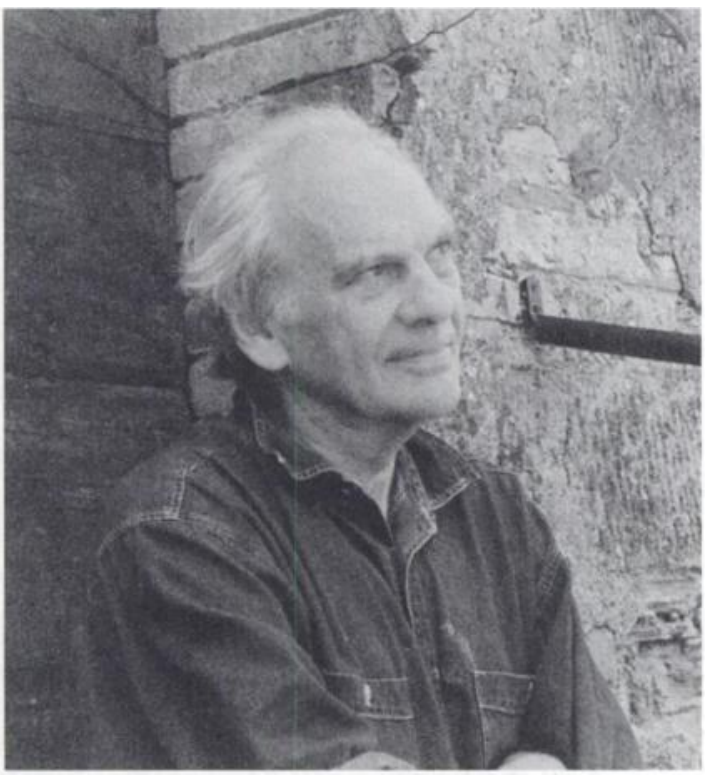

\section{Anthony Ryle}

Had I been invited to write a professional 'Prospect' when I qualified almost half a century ago, rather than this retrospect, it would have contained no reference to psychiatry or psychotherapy. Glimpses from the long stone corridor of Frien Barnet into vast bare wards inhabited by patients in striped hospital clothing (or has memory conflated this with images of Belsen?) and demonstrations of cases of, rather than of people with, echolalia or mania or 'general paralysis of the insane' (dementia paralytica), which were my student introduction to psychiatry, were aversive rather than attractive. But many of the values and attitudes which have shaped my later attitudes to psychiatry were already evident, rooted in the belief that the most destructive war in history should prepare the way for a juster world, and influenced by my father's enthusiastic advocacy of the National Health Service (NHS) and by his move from clinical to social medicine, a move through which he sought 'to study the ultimate as well as the intimate causes of disease'.
These influences, and a relative distaste and incapacity for the increasing biochemical core of medicine, determined my decision to go into general practice. I was lucky to find colleagues who shared my views and together we set up the Caversham Centre, a group practice which is now part of the Kentish Town Health Centre. At that time it was not difficult to improve on the standards of many urban working class practices. We offered an appointment system, we employed a practice nurse, we ran well-baby and antenatal clinics and we made full use of our examination couches, in contrast to some practices I had visited where they were piled high with unopened copies of the British Medical Journal. By knowing and doing little more than a competent final year student we were able to deliver good medical care and earned, I believe, the local bookie's runner's description of the practice (intended as a compliment) as "the poor man's 'arley street". Judging from the levels of skill I see today in my general practitioner (GP) son and his GP wife, however, we were seriously undertrained.

Within a few years I found myself being more curious about and concerned with my patients' problematic lives than with their diseases. I began to spend more time listening and talking to patients and I took up some clinical assistant sessions at the Royal Free with the aim of extending my skills. While I learned some psychiatry, I was left to work therapeutically largely on my own, it being the belief then, and perhaps still in some psychiatric quarters, that therapy requires no special training.

I also undertook some epidemiological research. GP NHS patient lists provided a population sample which, though local and perhaps idiosyncratic to the doctor, was not filtered by referral practices. Basic information about age, gender, and occupation were fairly reliably recorded, and other details such as the type of housing occupied supplemented these data. Combined with my own and previous records of consultations and referrals, my notes provided material for a sample survey of the practice population investigating the inception and prevalence rates by age and gender and social class of the common psychological disorders. The data was coded and transferred by hand onto punch cards which were sorted with a knitting needle, a 
method giving a concrete sense of the distribution of, and relations between, variables.

Around this time Desmond Pond (President of the Royal College of Psychiatrists, 1978-1981) suggested that we should evaluate the effect of placing a social worker in general practice, but I persuaded him that we first needed to establish the extent of the problems. We decided to focus on families with children at primary school, obtained research money from the Mental Health Research Fund and were joined by an experienced social worker, Madge Hamilton, who proceeded to interview the parents of over 100 families. From these interviews, my practice records, various psychometric tests and from school reports on the children, we were able to study the relations between the parents' life histories, mental health, marital relationships and child rearing practices, and the psychological status of the children. The findings demonstrated the transmission of psychological problems within the family, and we were able to argue with conviction for the family as being an appropriate focus for intervention and for primary care as being a good place to locate services.

Whether this study, which yielded a book and several papers, had any effect is doubtful; subsequent larger scale and more sophisticated surveys (which never referred to it) came up with largely parallel findings. It taught me a lot, however. I learned to value Madge Hamilton's unpretentious use of psychodynamic ideas, and her way of thinking about families. And from the many parents who commented on how moving and useful it had been to sit down with her through the long research interviews, I learned to appreciate the power of the listening professional to catalyse self-reflection.

At that time most long-term mental illness was treated in hospitals, but the drug revolution reached general practice in that letters from consultants about anxious or psychosomatic patients began to recommend chlordiazepoxide rather than phenobarbitone and tricyclic and monoamine oxidase inhibitor (MAOI) anti-depressants were available. Alerted by my clinical assistant sessions with Alick Elithorn at the Royal Free to what was then called mild endogenous depression. I was gratified by the transformation achieved by tricyclics in a few patients with long-term mild but pervasive mood disorders. Since that time, unlike some psychotherapists, I have never felt the need to choose between pharmacological treatment and psychotherapy; patients who need both should receive both. My prescribing of MAOIs, however, became extremely cautious after a patient of mine had what I believe was the first recorded hypertensive crisis following eating a yeast extract.
My lifelong ambivalence towards psychoanalysts was already in place, derived in part from my reading of Freud, whose insistence that one could not understand him until one had agreed with and submitted to his methods seemed unduly authoritarian and whose rapid transformations of assertions into assumptions still seem intellectually unrespectable. Two episodes served to illustrate my doubts. The first was reading through the past notes of a patient and finding a letter from the Tavistock Clinic describing how his immature and narcissistic character. manifest in his unrealistic plans to become a journalist, made him unsuitable for treatment. He was, when I knew him, sub-editor of a national newspaper. This taught me to be very cautious about recording predictions! The second episode was more tragic; called to visit a patient new to my list I found an old school friend, mute and standing stock still on one oedematous leg. The call had come from his (widowed and far from wealthy) mother who requested that I should arrange a London County Council ambulance to take him to his four or five weekly private psychoanalytic sessions in Hampstead. This I duly did, and the treatment must be regarded as a partial success in that, some three months later, the patient spoke as he got out of the ambulance on returning home after a session, saying "That is the last time I will go and see that fucker".

But my attitude to psychoanalysis was not simply negative, and I was glad of its guidance when my listening to patients began to evoke powerful transference attachments and rejections and I welcomed the attempt it made to understand personality in terms of developmental processes.

In 1964 the new University of Sussex advertised for a Director of the University Health Service. The common problems of students are psychological, and the university setting offered more time for training and research than general practice, so I applied and was very pleased to get the job. The University was in its third year, entering a phase of rapid expansion and offering the academic excellence of 'Balliol by the sea' combined with a serious commitment to the broader needs and circumstances of students. A consultant psychoanalytic psychiatrist. Fred Shadforth, had already been appointed; over the next decade he provided me and all the growing staff with generous support and supervision in a Winnicottian-Kleinian mode.

There was no shortage of psychologically disturbed students needing assessment and therapy, and research soon confirmed what other studies had shown, namely that such disturbance, as well as causing widespread distress, was frequently associated with failure and dropping-out of the university. But whereas 
Oxford, where these findings and the occurrence of disturbingly high suicide rates had been identified in the 1940s, was then in its third decade of discussions on whether or not to provide some counselling or medical care, Sussex set up from the beginning a system of personal tutors and sub-deans with links with the Health Service which sought to identify early, and assess accurately, students who were at risk. The system, of course, worked imperfectly, but I believe that, through it, teaching faculty achieved a more complex understanding of the causes of student failure and that many students benefited from this, as well as from the direct psychotherapeutic help we could provide in the Health Service.

As the University expanded, the staff of the Health Service was increased in proportion, and a close working group of doctors and nurses evolved which cared for the largely minor physical illnesses of this basically healthy population and provided much brief counselling and much formal individual and group psychotherapy. The small sickbay provided single rooms which could be used for the brief admission of patients in psychotherapy going through regressive or particularly distressed phases. Here, the increasingly sophisticated nursing staff provided tactful containment while the patients continued to see their therapists, often communicating through writing and painting; some of these patients made rapid and profound changes. Such protected spaces are hard to find in psychiatric hospitals or in therapeutic communities. I submitted an account of this work in a paper which was rejected with the referee's comment that it reads more like a fairy tale than a scientific paper'.

The main focus of my research soon shifted closer to my clinical work, and was heavily influenced by Kelly and repertory grid techniques. Over the next fifteen years, with support from the Medical Research Council and much help from Patrick Slater, I applied this simple, ingenious and still neglected method to the study of my psychotherapy patients and some other groups. My psychotherapy reflected a basically object-relations and group analytic theoretical orientation but my reservations about psychoanalysis had not gone away, and, as I read more widely and struggled to understand what psychoanalytic writers meant and as I tried to link psychoanalytic ideas to my clinical work and to the repertory grid data, I became increasingly interested in integrating the ideas and methods of the different psychotherapies.

In the mid-1970s chilly pre-Thatcherite winds manifested themselves in a committee chaired by the Registrar and informed by a professional review' of the Health Service (based on a 25 minute visit by a renal physician) which reached the clearly foregone conclusion that the service should be cut and recommended that I should re-direct my energies to the general practice care of students. Fortunately the terms of my contract precluded that, and I was bought off by a halftime 'research fellow' appointment and (very) early retirement. This experience enhanced my empathy with the many others who, in recent years, have been so little valued that they have been paid not to work.

I was, however, left with more time for research. I had long been annoyed by Eysenck's crude dismissals of dynamic psychotherapy and also long frustrated by the failure of dynamic therapists to respond. To assess the outcome of a treatment one needs measures related to its aims; in the case of dynamic therapy these go beyond symptomatic and behavioural changes to the revision of underlying structures and processes. I had already used repertory grid methods to demonstrate that such changes were achieved. To look at the process of change. I now studied the notes of a series of completed psychotherapies to see what I and the patients had been occupied in doing. I found that the work was centred on identifying and confronting the ways in which the patients were failing to revise manifest but unrecognised harmful ways of thinking and acting. Non-revision could be accounted for in terms of three patterns, which I labelled traps, dilemmas and snags. These descriptions emerged in forms which owed something to the sequential descriptions of behaviour therapy (traps), something to the way repertory grids display the limited options open to individuals (dilemmas) and something to psychoanalytic understandings of the operation of (conscious or unconscious) guilt and to the understanding of the link between individual disturbance and family and group processes provided by family and systems approaches (snags).

The next step was to use the first sessions to therapy with new patients to determine what their particular patterns might be, so that we could see whether therapy changed them. At this point, what had started as a research procedure proved, to my surprise, to have a profound and positive impact on the course of therapy. In working out and describing their problem procedures (as they came to be called), patients began to recognise their operation and to revise them. This observation initiated the last and most satisfying phase of my career, the development of Cognitive Analytic Therapy (CAT), an approach which maintains as its core features the early description of problem procedures through the joint work of the patient and therapist, the use of these (high levels and general) descriptions by the patient to recognise and control damaging ways of acting and their 
use by the therapist to avoid reciprocating and reinforcing such damaging patterns.

Although these developments were satisfying, I had been left in a marginal situation professionally, even though the College had, in its wisdom or kindness, made me a Member. At Jim Watson's invitation I began to visit Guy's to supervise brief therapy, and through this I heard about, applied for and was appointed to the new Psychotherapy Consultant post at St Thomas's, so commencing my third career.

The post was only advertised because the College required training rotations to include psychotherapy teaching. Sargant, recently retired, was still a dominant influence. In this bastion of organic psychiatry my welcome was, predictably, less than rapturous, although at the personal level most of my colleagues were friendly and this was increasingly so as a new consultant generation was appointed. As the only psychotherapist serving a population of about 180000 I had clearly to decide where to put my energy. Training and service provision seemed more feasible projects than converting my colleagues to a more informed appreciation of the place of therapy in general psychiatry. Junior psychiatrists, rotating around a large geographical area and granted no regular sessions for therapeutic work or supervision, had to be keen to pursue any training, but a proportion did commit themselves and did good work. But it soon became clear that the only way to provide a service was to attract non-medical trainees. As soon as I was in post a large number of social workers, occupational therapists, nurses and others emerged from the shadows asking for supervision and they proved an excellent resource, but the rapid growth in referrals would not have been coped with but for the parallel accelerating demand for CAT training which yielded in addition an inexhaustible supply of trainees from outside the hospital prepared to see patients in return for supervision.

In order to try to meet the needs of the population of the catchment area, not just the demands of those who found their way to the head of the queue, a policy of offering only the minimum sufficient intervention was established. Very few patients received long-term treatment, the great majority, including those with personality disorders, being given 12-16 sessions of CAT. After a few years, with the appointment of a part-time group analyst, group therapy also became available, either as an alternative or following CAT for some patients. During my 10 years at St Thomas's I personally assessed around $1 \%$ of the adult population of the catchment area. Most of these, unless psychotic or seriously substance misusing, were treated in the unit by trainees. By the end of my 10 years my supervision was supplemented by just over one wholetime equivalent trained therapist, including the group analyst.

One might have thought that this service, offering cost-effective treatments designed for NHS circumstances, would have attracted the support, or even the enthusiasm, of management, but this was not the case. I will resist the revengeful desire to catalogue the indifference, obstructiveness and the lack of interest or concern with evidence I met with, before and after the so-called Health Service reforms, as I fought to get remotely decent accommodation. secretarial support and some trained staff. Since my retirement, the St Thomas's Unit has remained operational and effective but always under threat.

My fourth career - retirement - has spared me from daily confrontations with these problems, but it has been bitter to see the damage done to the Health Service by underfunding and the ideologically motivated changes of recent years. These have placed staff under immense strain and can only be understood as preparation for the introduction of the commercial managed care systems which have so distorted American health care. I only hope that this threat may have receded since 1 May 1997. In a world of exaggerated social inequalities and limited resources, I find the right of the already privileged to purchase privileged health care obscene.

Although retired, I am fortunate in having retained a foothold in the world in the form of a part-time appointment at the United Medical and Dental School at Guy's, which allows contact with patients and trainees and ongoing research. But it is clearly the right moment to take stock. On the negative side, I regret having done little to bridge the yawning gap between British psychiatry and psychotherapy. Psychology influences physiology and physiology influences psychology; whatever the direction of effect, the patient as a person deserves as much sophisticated understanding as does the patient as an organism. At present, British psychiatry offers very uneven levels of psychological and psychotherapeutic sophistication. The fault does not lie only with psychiatry, however, for psychotherapy within the NHS has been slow to understand the implications of providing a service to populations. I feel that the complacent and conservative institutions of psychoanalysis, teaching out of a tradition of private, prolonged, intensive and unevaluated practice and being responsible to no academic or Health Service body, have had too much influence. In particular, they should cease to have the power they presently have, at least south of Potters Bar, to determine who gets appointed to senior registrar psychotherapy posts. NHS consultants should be trained to meet their responsibilities to the populations they serve through familiarity with a range of largely time-limited, integrated, 
dynamic and cognitive-behavioural treatments, using methods evaluated by carefully designed and adequately subtle research. Good ideas and practices from whatever source will survive in such a climate. Psychoanalytic theory should be studied elsewhere, in courses on the history of ideas.

On the positive side, I am glad to have made psychotherapy my final career and glad to have survived in it without having had to commit myself to any one training or institution. Perhaps I acquired from my great-grandfather, a bishop with ecumenical concerns, an integrating zeal which makes me impatient of the way in which the world of therapy is divided up into separate parishes, each with its own faith and its own parish magazine. I believe we need more debate and in particular I believe that CAT has something to offer to those whose ideas are closest, such as psychoanalytic attachment theorists, constructivists and cognitive therapists, while its challenge to the dominant current schools deserves to be argued with and not ignored.

Looking back on the ideals and values with which I set out, I am satisfied with the way CAT has become a developed and developing theory which emphasises the generally neglected social context and cultural determinants of individual personality. We are distinctly human in that our internal dialogue and our relations with others are mediated and structured in ways which derive from, and connect us with, the ongoing history and conversation of mankind. In this I follow - in a different field - my father's concern with the 'ultimate as well as the intimate' sources of pathology. And in developing an approach designed to be applicable and cost-effective in the public service I maintain loyalty to a democratic ideal for medicine.

Anthony Ryle, ACAT Office, Munro Clinic, Guy's Hospital, London SE1 9RT

\section{The Psychotherapy of Psychosis}

\section{Edited by Chris Mace and Frank Margison}

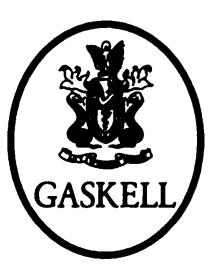

This book provides an unusually comprehensive survey of the current state and prospects of psychological methods of treatment for people with schizophrenia and other psychotic illnesses. It will be an invaluable resource for mental health professionals and clinical managers involved in their care, and essential reading for psychiatrists at all levels of experience.

The three traditions of psychotherapy and integrated approaches are covered. Recent research in the process and outcome of psychotherapy is reviewed and summarised. Clear advice is also given on treatment techniques and settings with reference to national policies. As with other titles in the series, there is frequent use of boxes, tables and figures to set out important points and key information. 1997, 296pp, ISBN $1901242048, £ 25.00$

Gaskell publications are available from Booksales, Publications Department,

Royal College of Psychiatrists, 17 Belgrave Square, London SW1X 8PG

(Tel. +44(0)171 235 2351, extension 146). The latest information on College publications is available on the INTERNET at: http://wwrw.demon.co.uk/rcpsych/ 